Dhaka Univ. J. Biol. Sci. 24(2): 111-119, 2015 (July)

\title{
THE USE OF BIOCHAR AS AMELIORATOR FOR SOIL ARSENIC
}

\author{
Nadia Noor, Kishan Mahmud, Md. Tanvir Ahmed Chowdhury \\ AND S.M. IMAMUL HuQ* \\ Bangladesh-Australia Centre for Environmental Research, Department of Soil, \\ Water and Environment, University of Dhaka, Dhaka-1000, Bangladesh
}

Key words: Biochar, Biomass, Ameliorator, Ipomoea aquatica, Arsenic

\begin{abstract}
Biochar and biomass were applied at the rate of $5 \mathrm{t} / \mathrm{ha}$ to soils that received arsenic containing water at a rate of $1 \mathrm{mg} / \mathrm{l}$ arsenic $(80 \%$ arsenite and $20 \%$ arsenate). After 36 days of growth of Kalmi plants, the yield parameters, such as arsenic accumulation and fate of arsenic vis-á-vis biochar addition had been examined. The results showed that the addition of biochar had a positive but non-significant impact on the yield parameters. Addition of biochar in the soil insignificantly increased the number of plants and the uptake of arsenic while the concentrations of extractable arsenic in soil decreased with biochar treatments. Source of biochar has a role to play towards this direction.
\end{abstract}

\section{Introduction}

Soil and ground water contamination due to arsenic (As) has been termed as the world's biggest natural calamity in known human history ${ }^{(1)}$. The widespread use of arsenic contaminated groundwater for irrigation has been reported to pose the risk of soil build up of arsenic and its subsequent transfer to plants ${ }^{(2-6)}$. Bangladesh is currently facing the challenge of mitigating soil contamination related to arsenic-laden ground water irrigation as the groundwater level of arsenic in this region is very high ${ }^{(7)}$. About $40 \%$ of total arable land of Bangladesh is now under irrigation, and more than $60 \%$ of irrigation needs are met from groundwater extracted by deep tube-wells, shallow tubewells or hand tube-wells ${ }^{(3)}$. Numerous greenhouse/field studies have found that an increase in arsenic in cultivated soil leads to an increase in the levels of arsenic in edible vegetables and ultimately end up in the human and animal bodies causing various disorders $^{(8-9)}$. Various approaches have been tested so far for mitigating arsenic problem and keeping the food source arsenic free. These included among others, selection of arsenic non-accumulating plants, mixing fresh water with arsenic-contaminated irrigation water for soil clean up, phytoremediation with indigenous plant species, use of green algae as a bioremediator for rice, and manipulating the water regime in rice culture etc. Although some of these approaches appeared promising but their field verification and carryover effects on various soil characteristics remained to be further ascertained ${ }^{(1)}$.

*Author for correspondence: <imamhuq@hotmail.com>. 
Use of organic matter, mostly cow-dung and poultry manure showed some positive effect in reducing the arsenic accumulation in plants( ${ }^{(7)}$. There is always a scope to try a new source or approach to mitigate this severe problem. Arsenic can be retained in the soil by increasing the surface area of soil phase and by forming complexes with soil or by using other materials that are not harmful for soil or plant. In this context, biochar could be a good option as the high surface area and porosity of biochar are able to sorb or retain nutrients and water and also provide a habitat for beneficial microorganisms to flourish $^{(10-12)}$.

Biochar has been credited with multiple benefits, including the ability to improve soil fertility, protect water quality, and generate carbon neutral energy. The use of biochar has, however, been argued to have some disadvantages, with some research reporting negative consequences on soil and crop production ${ }^{(13)}$. The present work has been attempted to study the effect of different sources of biochar in mitigating soil arsenic problem and to see the effect of biochar on the phytoavailability of arsenic.

\section{Materials and Methods}

Soil sample was collected from the Jagir Dighulia village of Atigram union, Manikganj Sadar Upazila in Manikganj district $\left(23^{\circ} 51.884 \mathrm{~N}\right.$ and $\left.90^{\circ} 06.219 \mathrm{E}\right)$, Bangladesh. It is a young Brahmaputra floodplain soil belonging to the Melandaha series. According to the USDA soil taxonomy the soil is a typic endoaquepts and according to the FAO-UNESCO legend it is a Gleysol (Eutric Gleysol). The bulk of soil samples $(0-15 \mathrm{~cm})$ were collected by composite soil sampling method(14) and processed $^{(15)}$.

Three different sources of biomass/feedstock materials i.e., locally collected rice straw, rice husk and sawdust were used to prepare biochars. The bulk biomass sample was air dried, ground and screened through a $5 \mathrm{~mm}$ sieve and used for biochar production by pyrolysis process.

Biochar was produced by following a simple version of pyrolysis process ${ }^{(16)}$. A portion of the biochar samples were sieved through a $0.25 \mathrm{~mm}$ sieve for different chemical and physico-chemical analysis and another portion with $0.5 \mathrm{~mm}$ sieve for pot experiment.

A pot culture experiment was conducted with an upland leafy-vegetable commonly known as Kalmi Sak (Ipomoea aquatica) using the following 7 treatments (three replications of each) arranged in a completely randomized design in the net house (Table 2).

Plastic pots $(120 \mathrm{~mm} \times 145 \mathrm{~mm})$ without hole at the bottom were filled with $2 \mathrm{~kg}$ soil ( $5 \mathrm{~mm}$ sieve) per pot and mixed with biochar and biomass samples at the rate of 5 ton/ hectare together with RDF for Kalmi Sak ${ }^{(17)}$. The pots were kept at ambient condition for 
15 days for the organic sources (biomass and biochar) to be stabilized when the seeds were sown.

Locally collected seeds of Kalmi Sak (9 - 10 seeds per pot) were sown in each pot. After germination, 7 seedlings were kept in each pot and allowed to grow. After three days of sowing, arsenic (As) @ $1 \mathrm{mg} / \mathrm{l}$ in water was applied everyday at a rate of 100 $\mathrm{ml} /$ day as irrigation water. The solution was made with a combination of $80 \%$ arsenite and $20 \%$ arsenate. Meta arsenite $\left(\mathrm{NaAsO}_{2}\right)$ and sodium arsenate $\left(\mathrm{Na}_{2} \mathrm{HAsO}_{4} \cdot \mathrm{H}_{2} \mathrm{O}\right)$ were used as a source of arsenite and arsenate, respectively.

The plants were allowed to grow for 35 days and then uprooted carefully. The plants were dried and processed ${ }^{(15)}$. After harvest the soil samples from each pot was also collected and processed as described above.

Various physico-chemical properties of the soil, biomass and biochar samples were analyzed in the laboratory ${ }^{(15)}$. Soil arsenic (both pre- and post experiment) was extracted using aqua regia, while the arsenic in the plant, biochar and biomass materials were extracted using concentrated $\mathrm{HNO}_{3}{ }^{(18)}$. The arsenic in the extract was estimated by using Hydride Generation Atomic Absorption Spectrophotometery (HGAAS)(18). For every ten samples a certified reference material (CRM) was included to ensure the QC/QA. All the statistical analyses were done by using MINITAB (version 16) Package.

\section{Results and Discussion}

Laboratory analysis ${ }^{(15)}$ of soil was done for $\mathrm{pH}(6.5)$, CEC (14.7 meq\%), textural class (silt loam), organic carbon $(0.33 \%)$, total $\mathrm{N}(0.042 \%)$, available $\mathrm{N}(0.004 \%)$, available $\mathrm{P}$ $(5.21 \mathrm{mg} / \mathrm{kg})$, available $\mathrm{K}(4.20 \mathrm{mg} / \mathrm{kg})$, and arsenic $(3.18 \mathrm{mg} / \mathrm{kg})$. Background analysis of biomass and biochar showed that both the materials contained some arsenic, more in the biochar (Table 1). Though rice husk did not contain any detectable arsenic, the corresponding biochar, however, contained a substantial amount of the element. This indicates that pyrolysis has concentrated the arsenic of the biomass.

Table 1. Chemical and physico-chemical properties of biomass and biochars.

\begin{tabular}{llllllll}
\hline \multirow{2}{*}{ Properties } & \multicolumn{3}{c}{ Biomass } & & \multicolumn{3}{c}{ Biochar } \\
\cline { 2 - 3 } \cline { 6 - 8 } & Bm-1 & Bm-2 & Bm-3 & & Bc-1 & Bc-2 & Bc-3 \\
\hline pH & 7.60 & 6.60 & 6.10 & & 10.5 & 7.50 & 6.70 \\
CEC (meq \%) & 12.9 & 17.2 & 16.2 & & 16.0 & 20.2 & 17.5 \\
Total nitrogen (\%) & 0.29 & 0.76 & 0.17 & & 0.30 & 0.52 & 0.17 \\
Total phosphorous (\%) & 0.04 & 0.86 & 0.11 & & 0.15 & 1.70 & 0.48 \\
Total potassium (\%) & 0.26 & 0.76 & 0.29 & & 0.72 & 0.20 & 0.78 \\
Arsenic (mg/Kg) & 0.095 & BDL & 0.007 & & 0.44 & 0.21 & 0.12 \\
\hline
\end{tabular}

$\mathrm{BDL}=$ Below detection limit. Bm-1 = Rice straw biomass. Bm-2 = Rice husk biomass. Bm-3 = Sawdust biomass. Bc-1 = Rice straw biochar. Bc-2 = Rice husk biochar and Bc-3 = Sawdust biochar. 
The growth of shoot and root of Kalmi tended to be affected by the various treatments (Table 2). It was observed that the application of biochar and biomass to soils increased the plant growth except for rice straw biomass. The dry matter production on biochar treated soils was higher than on their corresponding biomass treated soil and among all the treatments, sawdust biochar appeared to be the best treatment in respect to plant production. Blackwell et al.(19) and Lehmann et al.(20) mentioned that biochar can be used as an amendment to improve soil quality and crop production in a variety of soils. So, the better plant production in biochar treated soil could be due to an improvisation of soil quality by biochar.

Table 2. Fresh and dry weight (gm/100 plants) production of different parts of Kalmi plant.

\begin{tabular}{lccccccc}
\hline Treatment & \multicolumn{3}{c}{ Fresh weight } & & \multicolumn{3}{c}{ Dry weight } \\
\cline { 2 - 4 } \cline { 7 - 8 } & Shoot + leaf & Root & Total plant & & Shoot + leaf & Root & Total plant \\
\hline Co & 29.83 & 4.58 & 34.41 & & 8.72 & 1.74 & 10.47 \\
Bm-1 & 30.35 & 3.90 & 34.25 & & 9.55 & 2.00 & 11.55 \\
Bm-2 & 42.91 & 4.88 & 47.79 & & 10.15 & 1.50 & 11.65 \\
Bm-3 & 44.56 & 5.64 & 50.20 & & 9.83 & 1.64 & 11.47 \\
Bc-1 & 37.95 & 4.65 & 42.60 & & 10.30 & 1.56 & 11.86 \\
Bc-2 & 49.45 & 5.46 & 54.92 & & 10.89 & 1.62 & 12.51 \\
Bc-3 & 48.37 & 6.21 & 54.57 & & 10.95 & 1.76 & 12.71 \\
LSD at 5\% & NS & NS & NS & & NS & NS & NS \\
\hline
\end{tabular}

$\mathrm{Co}=$ Control. $\mathrm{Bm}-1=$ Biomass rice straw. $\mathrm{Bm}-2=$ Biomass rice husk. $\mathrm{Bm}-3=$ Biomass saw dust.

$\mathrm{Bc}-1=$ Biochar rice straw. Bc-2 =Biochar rice husk. Bc-3 = Biochar saw dust and NS = Not significant.

Although biochar treatments have shown increased plant growth over the biomass treatments, the effect, however, was not significant at $5 \%$ level. This indicates that addition of biochar might not have any substantial positive effect on plant growth over organic matter addition albeit some superiority shown in the present experiments.

The concentration, uptake and transfer factor of arsenic in different parts (root and shoot + leaf) of Kalmi plant showed that the biochar and biomass treatments increased the arsenic concentration and the roots contained more arsenic than the corresponding aerial parts. In case of biomass treated soil, the maximum concentration of arsenic was found in plants grown on sawdust biomass treated soil. Arsenic concentration in the shoot was the minimum $(0.71 \mathrm{mg} / \mathrm{kg})$ for control plant and the maximum in the saw dust biomass treatment $(3.38 \mathrm{mg} / \mathrm{kg})$. In the root the maximum concentration was observed in plants grown on sawdust biomass treatment $(16.9 \mathrm{mg} / \mathrm{kg})$ while the minimum was observed for the control plants $(6.1 \mathrm{mg} / \mathrm{kg})$ (Table 3). 
In biochar treated soil, the maximum concentration $1.98 \mathrm{mg} / \mathrm{kg}$ on the aerial parts were obtained for the sawdust biochar treatment while the minimum was observed for rice straw biochar treatment $(1.5 \mathrm{mg} / \mathrm{kg})$. In the roots, rice husk biochar treated plant showed the maximum arsenic concentration of $10.40 \mathrm{mg} / \mathrm{kg}$.

Table 3. The concentration, uptake, transfer factor (T.F.) of arsenic in root and shoot + leaf of Kalmi plants and $\mathrm{pH}$ and arsenic concentration of soil after harvest.

\begin{tabular}{|c|c|c|c|c|c|c|}
\hline \multirow[b]{2}{*}{ Treatment } & \multicolumn{2}{|c|}{ Uptake ( $\mu \mathrm{g} / 100$ plants) } & \multirow{2}{*}{$\begin{array}{c}\text { *T.F. for } \\
\text { total } \\
\text { plant }\end{array}$} & \multicolumn{3}{|c|}{ After harvest soil } \\
\hline & Shoot + leaf & Root & & $\begin{array}{c}\text { pH after } 30 \text { days } \\
\text { of incubation }\end{array}$ & $\begin{array}{l}\text { pH after } \\
\text { harvest }\end{array}$ & $\begin{array}{c}\text { As } \\
\text { (mg/pot) }\end{array}$ \\
\hline $\mathrm{Co}$ & $5.85(0.71)$ & $9.69(6.1)$ & 2.14 & 5.31 & 6.10 & 2.98 \\
\hline Bm-1 & $12.64(2.93)$ & $10.44(6.9)$ & 3.01 & 5.30 & 6.62 & 8.73 \\
\hline $\mathrm{Bm}-2$ & $19.93(1.92)$ & $10.99(7.4)$ & 2.93 & 5.45 & 6.40 & 7.56 \\
\hline $\mathrm{Bm}-3$ & $19.27(3.38)$ & $22.71(16.9)$ & 6.37 & 5.34 & 6.44 & 9.06 \\
\hline Bc-1 & $31.60(1.50)$ & $14.62(9.4)$ & 3.01 & 5.76 & 6.53 & 6.15 \\
\hline Bc-2 & $21.84(1.96)$ & $17.37(10.4)$ & 3.66 & 5.43 & 6.51 & 8.45 \\
\hline Bc-3 & $27.50(1.98)$ & $13.28(7.3)$ & 2.82 & 5.76 & 6.31 & 8.22 \\
\hline
\end{tabular}

*T.F. = Total As conc. in plants $\div$ As conc. in soil. Figures in the parentheses indicate the concentration of arsenic in $\mathrm{mg} / \mathrm{kg}$.

The uptake of arsenic by the Kalmi plants was higher in the biomass and biochar treatments over control (Table 3). Uptake in the aerial parts (shoot + leaf) was greater than in their roots except for the control and saw dust biomass treatments, where the scenario was reverse in case of arsenic concentration (more in roots). Further, uptake of arsenic in the biomass treated plants is in general, less than the biochar treated one (except sawdust biomass).

For the biomass treatments, As uptake in shoot + leaf and root was the maximum in rice husk (19.93 $\mu \mathrm{g} / 100$ plants) and sawdust treatments $(22.71 \mu \mathrm{g} / 100$ plants), respectively. For biochar, the maximum uptake in the edible part was $31.60 \mu \mathrm{g} / 100$ plants for rice straw biochar and in the root it was $17.37 \mu \mathrm{g} / 100$ plants for rice husk based biochar.

No significant effect of the treatments on either the root or the shoot arsenic concentrations ( $\mathrm{p}$ value 0.101 and 0.109 , respectively) was found from ANOVA test. In case of uptake the effect has been found significant for the root $(p=0.007)$ but not for the edible part $(p=0.134)$. The As contents in soils after harvest was significantly affected by the treatments $(p=0.003)$ at $5 \%$ level.

Sources of arsenic in the growth medium were the native amount in soil plus the amount added from irrigation water as well as some from the biomass/biochar. The transfer factor of arsenic was greater in the plants grown on soils treated either with biomass or biochar than in the control plants (Table 3). As to the effect of treatments, the 
transfer factor was the maximum in the saw dust (6.37) biomass treatment and the minimum was in its corresponding biochar (2.82) treatment. According to Fargo and Mehra ${ }^{(21)}$, when the plant/soil ratio for any particular element is 0.1 , the plant can be considered as excluding the element from its tissues. In the present study, Kalmi plants have shown the reverse phenomenon, indicating their affinity for arsenic accumulation.

The results of concentration, uptake and transfer factor of arsenic showed that the biochar treatments have no positive impact in reducing arsenic content in the Kalmi plants. The results of all these parameters were higher for the biochar and biomass treated soils over the control. But some biochar treatments appeared to be better than the biomasses. It is also observed that, while the concentration of arsenic was higher in the root, the uptake however, was higher in the edible part in all the experimental pots. This is due to greater biomass production of the aerial parts. This has a different connotation that more of the toxic element is removed from soil to the human body through the edible part of Kalmi when it is consumed. The increasing arsenic content of plants in biochar treated soil could be due to several reasons. The background analysis showed that the biochar itself contained some arsenic and it was more than its corresponding biomasses. The addition of these biochar increased the total soil arsenic and as a consequence the plant has taken up more of it. The $\mathrm{pH}$ condition could be another factor for the increasing arsenic content in the plants. Chan and $\mathrm{Xu}^{(22)}$ in their work showed that the increased $\mathrm{pH}$ in the biochar treated soil increased arsenic solubility by creating an alkaline condition. In the present case, it has been observed that the $\mathrm{pH}$ of the biochar and biomass treated soils increased after 30 days of incubation ${ }^{(23)}$ as well as at harvest (Table 3). Moreover, the $\mathrm{pH}$ of the biomass and biochars were greater than the soil $\mathrm{pH}$.

The experimental soil contained high amount of iron $(1.605 \%)$ and the biochar increased it by supplying $0.214,0.192$ and $0.232 \%$ from Bc- $1, \mathrm{Bc}-2$ and Bc-3, respectively. It is known that arsenic and iron combine with each other and forms inorganic arsenic compound. So the biochar might have retained the iron in their particle surface, making the arsenic free in the soil solution. The present findings corroborate with the work of Nguyen et al. (24).

A balance sheet to assess the fate of arsenic in the system is presented in the Table 4 . It is observed that, all the experimental pot initially contained $9.96 \mathrm{mg} /$ pot of arsenic. Some of this arsenic is taken up by the Kalmi plants. So, the excess amount of arsenic should remain in the soil after harvest. But the data indicate that there are some missing values, more in control than in the biochar or biomass treated soils. Among the biomass and biochar treated soils the missing amount of arsenic is higher in the biomass treated soil than in the corresponding biochar treated ones. The only exception observed was for rice husk biochar treatment. Nguyen et al.(24) have found that the biochar increases the concentration of extractable arsenic in biochar treated soil. This could justify the lesser amount of the missing arsenic in biochar treated soils. A part of the arsenic could be 
missing in the calculation because of its transformation through biomethylation (25). In addition, the solvent might have failed to extract a part of the arsenic sorbed onto the surface of soil colloids or the organic/char surfaces.

Table 4. Balance sheet for arsenic (mg/pot) in different experimental pot.

\begin{tabular}{lccccccc}
\hline \multirow{2}{*}{ Arsenic (mg/pot) } & \multicolumn{7}{c}{ Experimental pot } \\
\cline { 2 - 8 } & Co & Bm-1 & Bm-2 & Bm-3 & Bc-1 & Bc-2 & Bc-3 \\
\hline Initial content in the soil & 6.36 & 6.36 & 6.36 & 6.36 & 6.36 & 6.36 & 6.36 \\
Amount added through irrigation & 3.60 & 3.60 & 3.60 & 3.60 & 3.60 & 3.60 & 3.60 \\
From biomass/ biochar source & 0.00 & 0.0005 & $\mathrm{BDL}$ & 0.0000 & 0.0022 & 0.0011 & 0.0006 \\
Total arsenic content in the pot (a) & 9.96 & 9.96 & 9.96 & 9.96 & 9.962 & 9.961 & 9.96 \\
Removed through plant uptake (b) & 0.005 & 0.008 & 0.008 & 0.018 & 0.005 & 0.011 & 0.008 \\
Present in soil after harvest (c) & 2.98 & 6.15 & 8.45 & 8.22 & 8.73 & 7.56 & 9.06 \\
& $(29)$ & $(61)$ & $(84)$ & $(82)$ & $(87)$ & $(75)$ & $(90)$ \\
b + c = d & 2.985 & 6.158 & 8.458 & 8.238 & 8.735 & 7.571 & 9.068 \\
Amount missing (a - d) & 6.975 & 3.802 & 1.502 & 1.722 & 1.227 & 2.39 & 0.892 \\
Per cent As not accounted for & 70.0 & 38.0 & 15.0 & 17.0 & 12.0 & 23.0 & 8.0 \\
\hline
\end{tabular}

$\mathrm{BDL}=$ Below detection limit. Figures in parentheses indicate the value in per cent over the total.

The present study suggests that biochars prepared from straw, husk of rice or sawdusts are not suitable for soil arsenic remediation. Biochar and the biomass treatments had no positive impact on the reduction of the plant concentration of arsenic. Although the biochar increased the plant accumulation of arsenic, it retained up to $90 \%$ of arsenic in the soil. The study also suggests that the source of biochar is also an important factor to determine its behavior; as a result its effects on remediating arsenic also depend on the source from which the biochar has been produced.

\section{References}

1. Imamul Huq SM 2008. Fate of arsenic in irrigation water and its potential impact on food chain. In: Arsenic Contamination of Groundwater: Mechanism, Analysis, and Remediation (Ed. Ahuja S.). John Wiley \& Sons, Inc. ISBN 978-0-470-14447-3. pp. 23-49.

2. Ali MA, ABM Badruzzaman, MA Jalil, MD Hossain, MF Ahmed, AA Masud, M Kamruzzaman, and MA Rahman 2003. Arsenic in soil and plant environment of Bangladesh. In: Fate of Arsenic in the Environment (Eds. Feroze MA, AM Ashraf, and Z Adeel). Bangladesh University of Engineering and Technology, Dhaka, Bangladesh and United Nations University, Tokyo, Japan. ISBN 984-32-0507-3. pp. 85-112.

3. Imamul Huq SM and R Naidu 2005. Arsenic in groundwater and contamination of food chain: Bangladesh scenario. In: Natural Arsenic in Ground Water: Occurrence, Remediation and Management (Eds. Bundschuh, Bhattacharya and Chandrashkharam). Taylor and Francis Group, London. ISBN 041536700 X. pp. 95-102. 
4. Williams PN, MR Islam, EE Adomako, A Raab, SA Hossain, YG Zhu, J Feldmannand, and AA Meharg 2006. Increase in rice grain arsenic for regions of Bangladesh irrigating paddies with elevated arsenic in groundwaters. Environ. Sci. Technol. 40: 4903- 4908.

5. Meharg AA, M Abedin, M Rahman, J Feldmann, J Cotter-Howells and MS Cresser 2001. Arsenic uptake and metabolism in Bangladesh rice varieties. In: Book of Abstracts: Arsenic in the Asia-Pacific Region Workshop. Adelaide, South Australia, 20-23, November, 2001. pp. 45-46.

6. Farid ATM, KC Roy, MK Hossain and R Sen 2003. A study of arsenic contaminated irrigation water and it's carried over effect in vegetables. In: Fate of Arsenic in the Environment (Eds. Ahmed MF, MA Ali and Z Adeel). Bangladesh University of Engineering and Technology, Dhaka, Bangladesh and United Nations University, Tokyo, Japan. pp. 113-121.

7. Imamul Huq SM, AS Mamun, JC Joardar and SA Hossain 2008. Remediation of soil arsenic toxicity in Ipomea aquatica using various sources of organic matter. J. Land Contam. Reclam. 16(4): 333-341.

8. Joardar JC, MH Rashid and SM Imamul Huq 2005. Adsorption of arsenic (As) in soils and in their clay fraction. Dhaka Univ. J. Biol. Sci. 14(1): 51-61.

9. Imamul Huq SM, R Correll and R Naidu 2006. Arsenic accumulation in food sources in Bangladesh: Variability with soil type. In: Managing Arsenic in the Environment: From Soil to Human Health (Eds. Naidu R, E Smith, G Owens, P Bhattacharya and P Nadebaum). CSIRO Publishing, Melbourne, Australia. pp. 283-290.

10. Glaser B, J Lehmann and W Zech 2002. Ameliorating physical and chemical properties of highly weathered soils in the tropics with charcoal. Biol. Fertil. Soils 35: 219-230.

11. Lehmann J and M Rondon 2006. Biochar soil management on highly weathered soils in the humid tropics. In: Biological Approaches to Sustainable Soil Systems (Ed. Uphoff N). CRC Press, Taylor and Francis Group, Florida. pp. 517- 530.

12. Warnock DD, J Lehmann, TW Kuyper and MC Rillig 2007. Mycorrhizal responses to biochar in soil-concepts and mechanisms. Plant and Soil 300: 9-20.

13. McClellan T, J Deenik, G Uehara and M Antal 2007. Effects of flashed carbonized macadamia nutshell charcoal on plant growth and soil chemical properties. Paper presented at "ASACSSA-SSA International Annual Meetings", held at New Orleans, Louisiana, November 6, 2007.

14. USDA (United States Department of Agriculture) 1951. Soil Survey Manual. Soil Survey Staff, Bureau of Plant Industry, Soils and Agricultural Engineering, United States Department of Agriculture, Washington. Handbook No. 18. pp. 205.

15. Imamul Huq SM and MD Alam 2005. A Handbook on Analyses of Soil, Plant and Water. BACERDU, University of Dhaka, Bangladesh. pp. 1-246.

16. Mahmud K, MS Chowdhury, N Noor and SM Imamul Huq 2014. Effects of different sources of biochar application on the emission of a number of gases from soil. Can. J. Pure and App. Sci. 8(2): 2813-2824.

17. BARC 2005. Fertilizer Recommendation Guide-2005. BARC Soils Publication No. 45. Published by BARC, Dhaka. pp. 1-254.

18. Portman JE and JP Riley 1964. Determination of arsenic in seawater, marine plants and silicate and carbonate sediments. Anal. Chem. Acta. 31: 509-519. 
19. Blackwell P, G Reithmuller and M Collins 2009. Biochar application to soil. In: Biochar for Environmental Management: Science and Technology (Eds. Lehmann J and S Joseph). Earthscan, London. pp. 207-226.

20. Lehmann J, J Pereira, C Steiner, T Nehls, W Zechs and B Glaser 2003. Nutrient availability and leaching in the archaeological anthrosols and a ferrasol of the Central Amazon Basin: Fertilizer, manure and charcoal amendments. Plant and Soil 249: 343-357.

21. Farago ME and A Mehra 2003. Mechanism of copper tolerance by America maritima in Dolfrwynog, BOG, North Wales - Initial Studies. Environ. Geochem. Health 25: 147-156.

22. Chan KY and Z Xu 2009. Biochar: Nutrient properties and their enhancement. In: Biochar for Environmental Management: Science and Technology. Earthscan, London. pp. 67-84.

23. Khan KT, MTA Chowdhury and SM Imamul Huq 2014. Application of biochar and fate of soil nutrients. Bangladesh J. Sci. Res. 27(1): 11-26.

24. Nguyen BT, J Lehmann, J Kinyangi, R Smernik, SJ Riba and MH Engelhard 2008. Long-term black carbon dynamics in cultivated soil. Biogeochem. 89: 295-308.

25. Biswas A, JC Joardar, AFM Hoque and SM Imamul Huq 2009. Retention of irrigation water arsenic in a soil profile of Bangladesh. Bangladesh J. Agric. Environ. 5(2): 55-61. 